\title{
US hypersonics initiatives require accelerated efforts of the materials research community
}

$\mathrm{N}_{\mathrm{i}}^{\circ}$ o supersonic passenger aircraft has flown since the 2003 retirement of the Concorde, which crisscrossed the Atlantic Ocean at a top velocity of Mach 2.04 (2.04 times the speed of sound, or 1354 miles per hour). In comparison, the turboramjet engines of the US SR-71 military reconnaissance aircraft accelerated it to Mach 3.2, cutting the flight time from Los Angeles to Washington, DC, to 1 hour. While sustained interest in high-speed flight around the world - albeit without the distressing sonic boom - has brought forth designs for new, quieter supersonic aircraft, aerospace manufacturers and US Government departments and agencies have set their sights on even loftier targets. Design teams across the country are presently hard at work to realize hypersonic vehicles. As defined in a 2020 US National Academy of Engineering (NAE) report, hypersonic vehicles travel through air at speeds of Mach 5 or higher-over one mile every second.
Humans have traveled at these speeds through the atmosphere on many past occasions. Upon reentry, the Space Shuttle orbiters and the Apollo command modules reached, respectively, Mach 22 and Mach 32 velocities. They faced the same challenge that is now standing in the way of all earthbound hypersonic platforms: flight through the atmosphere at these speeds generates immense amounts of heat. A 1974 NASA Technical Note reported that, during reentry, the Apollo heat shield experienced a temperature swing from the $-150^{\circ} \mathrm{C}$ of deep space to a fiery $+2700^{\circ} \mathrm{C}$ within $14 \mathrm{~min}$ as it descended toward Earth. To protect the crew and equipment, its heat shield employed a polymer resin that ablated (vaporized) bit by bit and removed collected heat along with the ejected mass. As outlined in a 2008 American Institute of Aeronautics and Astronautics (AIAA) conference paper by David Glass, the aluminum frame of the Space

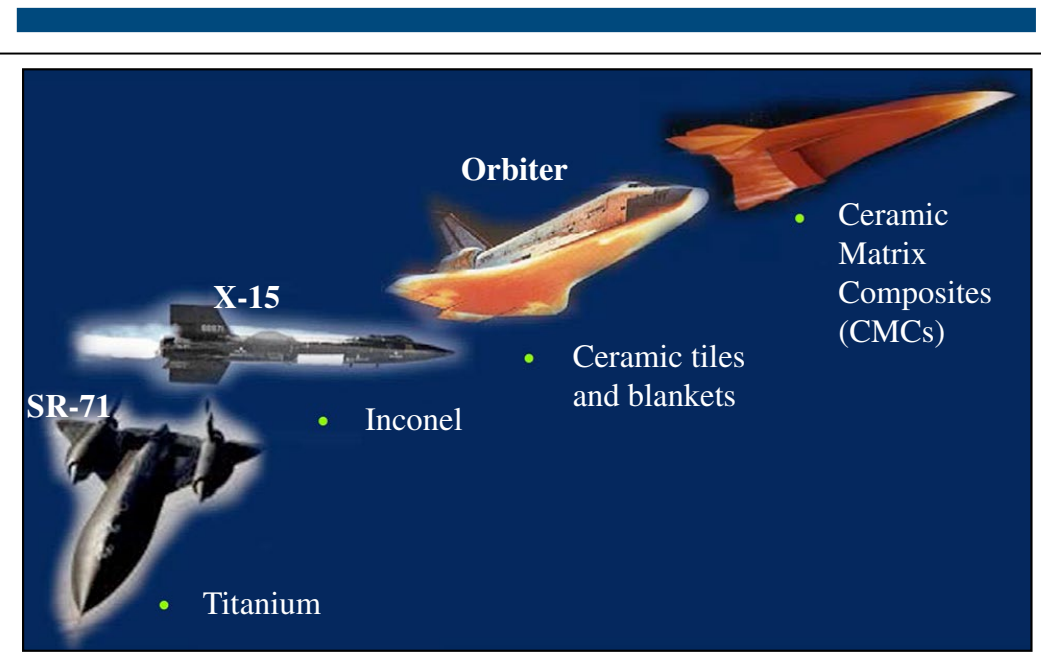

Outer shell materials enable aerospace vehicles to withstand extreme temperatures of their operating environments. Image credit: David Glass, "Ceramic Matrix Composite (CMC) Thermal Protection Systems (TPS) and Hot Structures for Hypersonic Vehicles," 15th AIAA International Space Planes and Hypersonic Systems and Technologies Conference, 2008.

Shuttle Orbiter was protected by carbon and ceramic composites and coatings that strategically shielded vehicle components as they experienced different heating regimes.

Hypersonics that stay in the Earth's atmosphere during their entire flight face an exponentially larger heat challenge. The well-recognized Apollo and Shuttle shapes, which expose the widest part of these vehicles to air, aim to slow down the spacecraft as quickly as possible; a 2004 NASA Technical Memorandum allocated only 30 minutes for a Space Shuttle's typical de-orbit maneuver. Moreover, neither could maneuver or adjust its trajectory during the fiery high-speed descent. As highlighted in a 2019 AIAA Information Paper, most promising hypersonic platforms rely on "lifting bodies" that feature sharp edges and minimal drag. Any sacrificial ablation of the heat shield disrupts airflow and, at these speeds, renders the vehicle uncontrollable. The 2003 Columbia Space Shuttle disaster serves as a tragic reminder of the consequences of a failed thermal protection system. Hypersonic vehicles require new materials to move beyond previously fielded technologies (shown in the Figure), as existing architectures cannot meet the challenges of controlled flight at 5-20 times the speed of sound across thousands of miles.

A 2020 Science article entitled "Need for Speed" outlined the various pursuits of novel hypersonic vehicles by the US Department of Defense (DoD) - the earliest of which date back to the 1940s. Interest in this technology has ebbed and flowed in the last half century. Although these efforts yielded several promising prototypes and materials architectures, no "finished product" flying vehicles emerged.

The last five years have corresponded with yet another resurgence 
in the US Government's interest in both piloted (i.e., winged airplanes) and unpiloted (i.e., rockets) hypersonic platforms. As a 2020 Congressional Research Service (CRS) report notes, newly fielded Mach 10-27 Chinese and Russian rocket prototypes have added a greater sense of urgency to this latest push. The NAE report highlights recent advances in computer modeling, design optimization strategies, new engine technologies, and materials breakthroughs that make a hypersonic flying vehicle more likely now than ever before. A 2019 Institute for Defense Analyses research insight into materials for extreme environments highlighted proliferation of materials databasesincluding high-entropy alloys and thermal-barrier coatings - that accelerate computationally driven discoveries and overcome existing hypersonics materials challenges. This combination of interest and new capabilities may provide the critical mass for interest in this technology to finally deliver.

A 2019 US Government Accountability Office Science and Technology Spotlight on Hypersonics identifies two main approaches that are shaping the design of these high-speed lifting bodies: a gliding vehicle (launched by a rocket into high altitudes) and an air-breathing counterpart (powered by a scramjet-supersonic-combustion ramjet-engine). Due to practical considerations, an unpiloted, singleuse platform is more likely to emerge before a piloted airplane can complete its inaugural flight at these speeds. As described in a 2017 RAND Corporation report on hypersonics technologies, each operational mode subjects the underlying vehicle to different mechanical and thermal stresses and, subsequently, requires different engineering designs. A 2015 US Air Force (USAF) Scientific Advisory Board assessment pegged the technology readiness level of a glide vehicle as having reached five out of the nine maximum milestones. At a 2019 Royal Aeronautical Society conference, a presentation by Lockheed Martin Corporation's Director of Technology and Innovation, David Hunn, highlighted key materials technologies and materials-driven cooling innovations that enable either platform to overcome the extreme heat challenge of flight above Mach 5.

In 2018, the DoD issued its newest National Defense Strategy that included hypersonics development as a key national security issue. As noted in the CRS report, DoD investment in this area for 2021 and 2022 fiscal years totaled, respectively, USD $\$ 2.6$ billion and USD \$3.2 billion. A June 2020 Presidential Determination listed industrial base production capability for high-temperature composites for hypersonic vehicles as essential to national defense, and, as such, falling within the scope of the Defense Production Act of 1950. And an August 2020 joint Memorandum from the Office of Management and Budget and the Office of Science and Technology Policy, which took into consideration exacerbating conditions of the COVID-19 pandemic, further reinforced hypersonic capabilities as a core Advanced Military Capability area for US Government agencies' leadership. In October 2020, the Pentagon announced its formation of the Joint Hypersonics Transition Office (JHTO) Systems Engineering Field Activity at Naval Surface Warfare Center, Crane Division. The 2020 National Defense Authorization Act, which appropriated USD\$100 million for this activity, aims to use JHTO to bring together industry and government partners to more rapidly field emerging technologies.

The CRS report further highlights different competing technologies that are being developed by each service branch along with the fact that completed and successfully demonstrated prototypes will likely drive any future acquisition and deployment efforts. Defense laboratories and DoD research funding agencies play prominent roles in materials research efforts for hypersonics. In December 2018, a news release from the Defense
Advanced Research Projects Agency announced its Materials Architectures and Characterization for Hypersonics Program. A February 2019 Air Force Research Laboratory Request for Information entitled "Manufacturing of Carbon-Carbon Composites for Hypersonic Applications" became available on the US Government main contract opportunities website. As reported in December 2020, its Medium Scale Critical Components test program yielded a successful test of an air-breathing scramjet prototype with record-setting thrust capabilities. And a 2019 National Academies of Sciences, Engineering, and Medicine 2017-2018 Assessment of the Army Research Laboratory notes the viability of its research into liquid propellants for potential hypersonic platforms. Recent US Naval Research Laboratory news releases have highlighted the Space Division's breakthrough "morphing waverider" concept, which demands shape-shifting materials components that will allow this unique hypersonic glider to successfully maneuver through upper atmosphere layers.

The DoD is not the only US Government department or agency that has an interest in materials that withstand extremes of Mach 5+flight. NASA's hypersonics research areas focus on blunt body reentry (for extraterrestrial missions) and atmospheric flight (for research activities, point-to-point travel, and servicing near-Earth orbit space missions). At its Ames and Langley Research Centers, the agency is developing new materials architectures, aeroshells, and heat shields that will protect exoplanetary landing craft during their entry into the atmospheres of Mars, Venus, moons of Jupiter and Saturn, and other celestial bodies. Under its Aeronautical research umbrella, researchers at the NASA Armstrong Flight Research Center are exploring adaptive guidance systems, modeling high-altitude environments, and designing high-temperature insulative and advanced composite materials. 
Other US Government departments and agencies are also leveraging their capabilities to bring forth new technologies that feed into emerging hypersonic platforms. Sandia National Laboratories (run by the Department of Energy, or DOE) operates prototype test beds that simulate environmental conditions of flight up to Mach 14. The National Security Programs division of DOE's Argonne National Laboratory is using the facility's Advanced Photon Source to examine propellant dynamics and flows in fuel injectors of scramjet engines that will enable the necessary thrust for hypersonic flights. In January 2017, a news release from a Materials Science and Technology Division research group at Oak Ridge National Laboratory highlighted its contribution to composite materials design of turbine blades that operate at unprecedented high temperatures. Finally, under its Manufacturing Extension Partnership program, the National Institute of Standards and Technology conducts extensive research of the defense manufacturing supply chain to assess the vitality of the Defense Industrial Base for hypersonic vehicle manufacturing.

This multitude of hypersonicsfocused US Government departments and agencies, private companies, and university partners relies on a robust national materials design and testing infrastructure. As noted in the CRS report, as of 2014, the United States possessed 48 specialized hypersonic test facilities, including $10 \mathrm{DoD}$ hypersonic ground test facilities, 11 DoD open-air ranges, 11 DoD mobile assets, nine NASA facilities, two DOE facilities, and five industry and academic facilities. However, the report goes on to highlight the fact that, in 2018, China conducted 20 times as many hypersonic tests as the United States. In a December 2020 interview with Air Force Magazine, USAF Chief Scientist Richard J. Joseph suggested that infrastructure and personnel available in the United States are insufficient to carry out the necessary work on all ongoing hypersonics efforts. Only specialized facilities can carry out this research, and their shortage is slowing down US progress in this race. Other countries are expanding into the space: Australia, India, France, and Germany have launched their respective hypersonics initiatives.

For development of piloted or unpiloted hypersonic vehicles that serve transportation, military, or scientific end users, subject matter expert shortage is a challenging hurdle on par with a backlog for wind tunnel testing. As noted in the September 2020 AIAA Information Paper on the aerospace and defense workforce, the field's human capital challenges include an aging workforce, a 3-to-1 male-female gender gap, and a lack of diversity among new hires. Education and interest in this field starts early through properly tailored engineering education, and shortcomings in relevant curricula and research activities can stymie interest in students across universities.

K.T. Ramesh, professor and director of the Hopkins Extreme Materials Institute at Johns Hopkins University, summarized this challenge:

The hypersonic applications environment is one of extremes. Materials research for hypersonic innovations must have access to cutting edge facilities that examine the extreme environment, and access to computational modeling that can integrate multiple physical processes - and people who can exercise both the facilities and the models. To attract such talent, and to hold it, we must have (i) significant investment in facilities; (ii) coordinated longterm research efforts that fund multidisciplinary work; and (iii) an emphasis on the fundamentals, not just the applications. At this time there are significant concerns: for example, the best people want to work in institutions with state-of-the-art facilities, and our pace of investment in facilities has lagged behind our competition.

\section{Boris Dyatkin}

We welcome comments and feedback in this article via email to Bulletin@mrs.org.

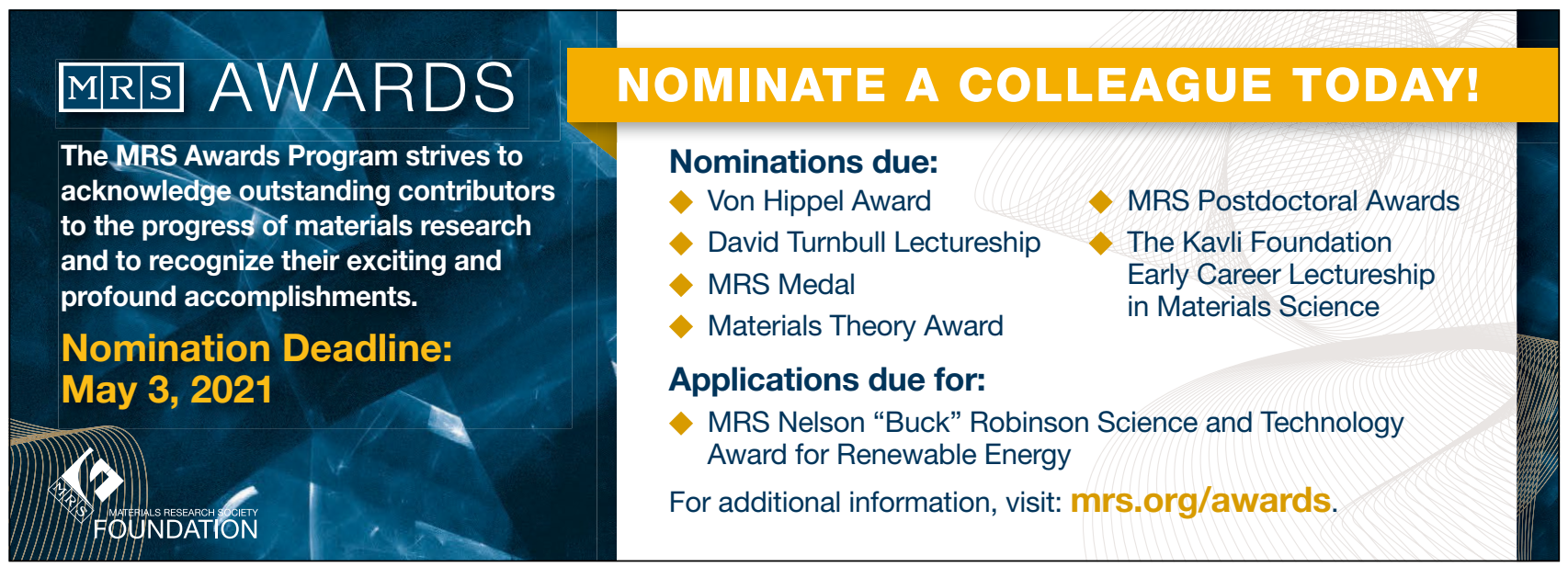

